$\xi=$ 줄

\title{
Evaluation of hybrid implant in posterior edentulous maxilla with inadequate bone
}

\author{
Dr. Aabu Varghese ${ }^{1 *}$, Dr. Varghese Mani ${ }^{1}$, Dr. Sankar Vinod V ${ }^{1}$, Dr. Arun George ${ }^{1}$ \\ ${ }^{1}$ Department of Oral and Maxillofacial surgery, Mar Baselios Dental College, Thangalam, Ernakulam,686691, Kerala, India \\ *Corresponding author E-mail: aabuvarghese@gmail.com
}

\begin{abstract}
Aim of this study is to investigate.

Hybrid implant has got satisfactory results in our previous study in various edentulous areas with inadequate bone for endosseous implant placement. The credibility of the implant in the areas of posterior maxilla needed to be evaluated.

Objectives

- To evaluate the hybrid implant postoperatively 18 months for gingival status, pain, peri-implantitis and mobility, so that it can be applied in posterior maxillary edentulous spaces with inadequate bone as an alternative to conventional implant.

Materials and methods

15 patients were rehabilitated in the posterior edentulous areas with hybrid implant. we intended to study the rehabilitation of posterior maxillary edentulous space i.e. Maxillary- premolar, 1st molar and 2nd molar area with hybrid implant and evaluate the hybrid implant post operatively for 18months (1stmonth, 3rd month, 6th month ,12 th month,18thmonth).

Results

- During the study period the implant system presented with no gingivitis, peri-implantitis, and pain.

- The periotest test values show the implant system to be very much stable.

- Also proves to be safe, economical and clinician and patient friendly compared to other implant systems.

Conclusion

- Hybrid implant system proves to be very effective in rehabilitating the posterior maxillary regions with inadequate bone.

- Also proves to be safe, economical and clinician and patient friendly compared to other implant systems.
\end{abstract}

Keywords: Hybrid Implant; Sinus Lift; Posterior Maxillary Edentulous Areas.

\section{Introduction}

In 2014 Varghese Mani et al $^{1}$ reported a novel implant system which can very well handle atrophic maxilla without sinus lift and grafting procedures .A report of two cases on atrophic posterior maxilla had been given with a follow up of one year. The implant showed good stability with minimum postoperative complication. Moreover the CBCT shows the implant osseointegrated with no peri -implant bone loss. Here we are reporting the results of fifteen implants placed in relation to posterior maxillary region and the stability of the implant has been tested with periotest post operatively at various intervals ( 1 st month, $3^{\text {rd }}$ month, $6^{\text {th }}$ month, $12^{\text {th }}$ month, $18^{\text {th }}$ month).

\section{Materials and methods}

POPULATION: All patients above 20 years who reported to outpatient department of Mar Baselios Dental College, Kothamangalam for replacement of the missing tooth according to the inclusion and exclusion criteria. All the patients were explained about the method of the study, about the new implant system, possible complications and other alternative methods of replacement of missing teeth and a detailed consent is taken from patients who are willing to participate in the study

Inclusion criteria

1) All patients above the age group of 20 years.

2) Patients who needs replacement of single or multiple teeth in the posterior maxillary edentulous spaces (maxillary -premolar, 1st molar, 2nd molar areas).

3) Proper oral hygiene.

4) Adequate patient compliance.

Exclusion criteria

1) Medically compromised patients.

2) Inadequate patient compliance.

3) Patients with craniofacial syndromes. 
4) Smokers

\section{Research design}

A prospective research design with a follow up during the $1^{\text {st }}$ month, $3^{\text {rd }}$ month, $6^{\text {th }}$ month, $12^{\text {th }}$ month and $18^{\text {th }}$ month postoperative periods.

After the placement of hybrid implant patients are evaluated for gingival status, peri implantitis, pain and mobility(with periotest) during the $1^{\text {st }}, 3^{\text {rd }}$ month, .During the third month the implant is loaded and again evaluated for the same at sixth month, $12^{\text {th }}$ month, $18^{\text {th }}$ month.

\section{Procedure of hybrid implant placement}

After giving a chlorhexidine rinse, operative site is wiped with gauze and local anaesthesia with adrenalin 1:200000 is given. A crevicular incision continued with a crestal incision followed by a vertical release incision in the anterior region is given. A triangular mucuperiosteal flap is elevated and the alveolar bone is exposed (FIG-1).

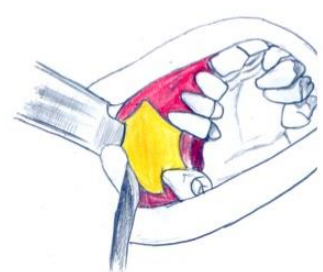

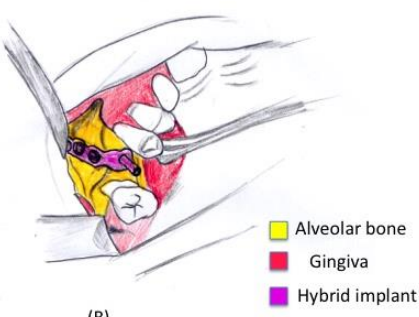

(B)

Fig. 1: (A) - Elevation of Mucoperiosteal Flap ,(B) -Adaptation of Hybrid Implant.

The implant is molded to the contour of the exposed alveolar bone in such a way that the abutment is projecting into the oral cavity in the direction of the tooth replaced. In cases of knife-edge ridge patterns a small crestal portion of the alveolar bone shaved to make the surface of the alveolus flat. This will aid in the submerging of the hybrid implant plate into the alveolar bone. After proper adaptation the implant is fixed to the alveolar bone using titanium screws of size $2 \times 6 \mathrm{~mm}$. Two screws are placed in the buccal part and one screw in the palatal region. Before closure of the mucoperiosteal flap a horizontal incision is placed only the periosteal part of the flap. This will aid in the proper closure of the flap. The closure is done with 3-0 silk suture. The abutment will be the exposed part of the implant projecting into the oral cavity in the direction of missing tooth. A course of antibiotics and analgesics is given for five days .Patient is recalled after 7 days for suture removal.

The implant is loaded after 3 months depending on the stability value checked with Periotest .The armamentarium required for the placement of hybrid implant are as follows (FIG-3)-

1) NO -16 BP blade and handle

2) Periosteal elevators - molt no 9, Howarths

3) Austin's retractor

4) Self-holding screw driver

5) $2 \times 6 \mathrm{~mm}$ titanium screws

6) Adsons tissue holding forceps

7) Suture material (3-0 Surgi silk)

8) Suture cutting scissors

9) Needle holder

10) Irrigation needle and syringe

11) Kidney tray

12) Suction apparatus

13) Plate bender

14) Micro motor headpiece and bur

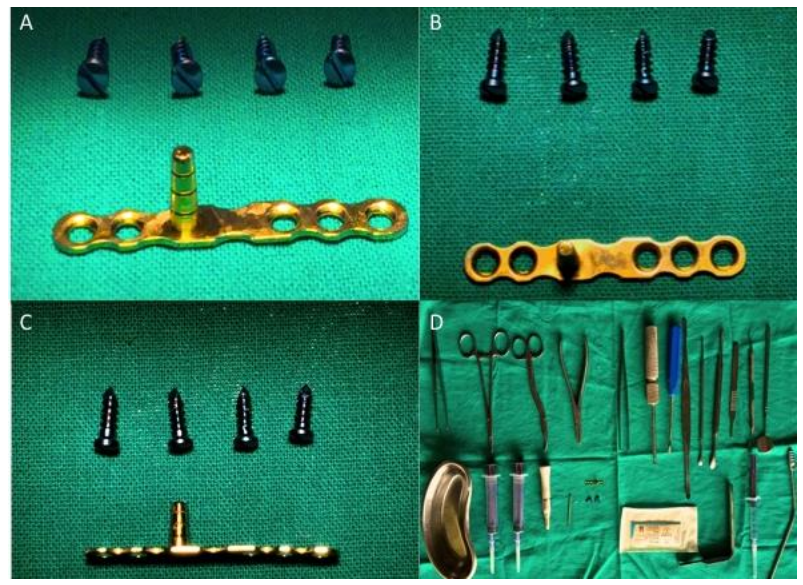

Fig. 2: A-Hybrid Implant View 1, B-Hybrid Implant View 2, C-Hybrid Implant View 3, C-Armamentarium for Hybrid Implant Placement. 


\section{Clinical pictures}

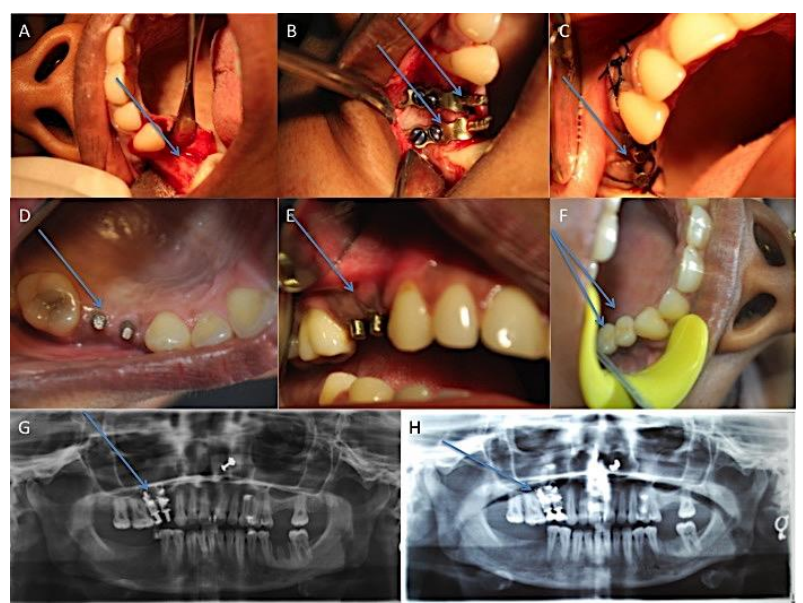

Fig. 3: Case 1 (A- Raising Mucoperiosteal Flap, B-Hybrid Implant Adapted and Fixed with 2x6 Mm Screws, C-Closure of Mucoperiosteal Flap, D \& E -3 Month Post-Operative Occlusal View and Buccal View , G -3 Month Post-Operative Opg Before Loading of Hybrid Implant, H-Post Loading 18 Months.).

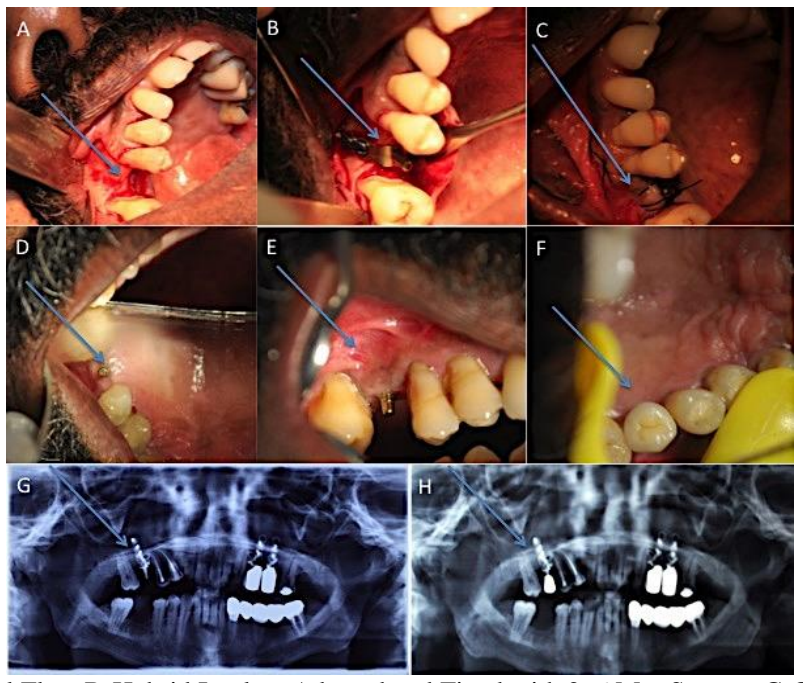

Fig. 4: Case 2 (A- Raising Mucoperiosteal Flap, B-Hybrid Implant Adapted and Fixed with 2x6 Mm Screws, C-Closure of Mucoperiosteal Flap, D \& E -3 Month Post-Operative Occlusal View and Buccal View , G -3 Month Post-Operative Opg Before Loading of Hybrid Implant, H-Post Loading 18 Months.)

\section{Statistical analysis}

In this study the patients who were implanted are checked for gingival index, pain, peri implantitis and mobility periotest during first month, third month, sixth month, one year and one and a half years. The frequency distribution of gingival index, pain, peri implantitis and mobility periotest during first month, third month sixth month, one year and one and a half years are calculated. Bar charts are also drawn. It is also tested if there is any significant difference in mean mobility periotest among the three months. Repeated measures ANOVA is used to for the analysis. In the analysis significance level is taken to be 0.05 (i.e., if the p-value is less than 0.05 , reject the null hypothesis or it can be concluded that the hypothesis is statistically significant) and the tests are two-tailed. The analysis is conducted using Microsoft Excel (2010) and SPSS (22.0.0.0)

\section{Study of age and sex}

The descriptive statistics of the age is obtained below. The mean value, standard deviation, maximum and minimum values of age are computed.

Table 1: Descriptive Statistics

\begin{tabular}{llllll}
\hline & $\mathrm{N}$ & Minimum & Maximum & Mean & Std. Deviation \\
\hline Age & 15 & 25.00 & 56.00 & 45.533 & 10.908 \\
\hline
\end{tabular}

From the above table it can be observed that the mean value of age is 45.533 years with a standard deviation of 10.908. The frequency distribution of sex is obtained below.

Table 2: Frequency Distribution of Sex

\begin{tabular}{lllll}
\hline Sex & Frequency & Percent & Valid Percent & Cumulative Percent \\
\hline Male & 12 & 80.0 & 80.0 & 80.0 \\
Female & 3 & 20.0 & 20.0 & 100.0 \\
Total & 15 & 100.0 & 100.0 & \\
\hline
\end{tabular}


The table above suggests that there are $12(80 \%)$ males and $3(20 \%)$ females in this study. A bar chart is also drawn below.

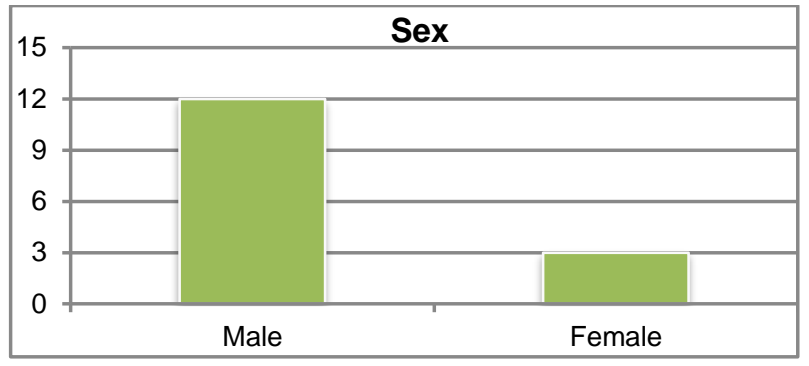

Fig. 1: Bar Chart of Sex.

Study of gingival index during first month, third month, sixth month, one year and one and a half years

The presence of gingival index during the first, third, sixth month, one year and one and a half years for the patients is studied. The frequency distribution is given below.

Table 3: Frequency Distribution of Gingival Index

\begin{tabular}{|c|c|c|c|c|c|c|}
\hline Gingival Index & $\begin{array}{l}\text { Month } \\
\text { First month }\end{array}$ & Third month & Sixth month & One year & One and a half year & Total \\
\hline No inflammation & 13 & 15 & 15 & 15 & 15 & 73 \\
\hline Mild inflammation & 2 & 0 & 0 & 0 & 0 & 2 \\
\hline Moderate inflammation & 0 & 0 & 0 & 0 & 0 & 0 \\
\hline Severe inflammation & 0 & 0 & 0 & 0 & 0 & 0 \\
\hline Total & 15 & 15 & 15 & 15 & 15 & 75 \\
\hline
\end{tabular}

From the above table it can be observed that out of the 15 patients, 13 patients had no inflammation of gingival index. Only 2 patients had mild inflammation.

The bar chart is also given below.

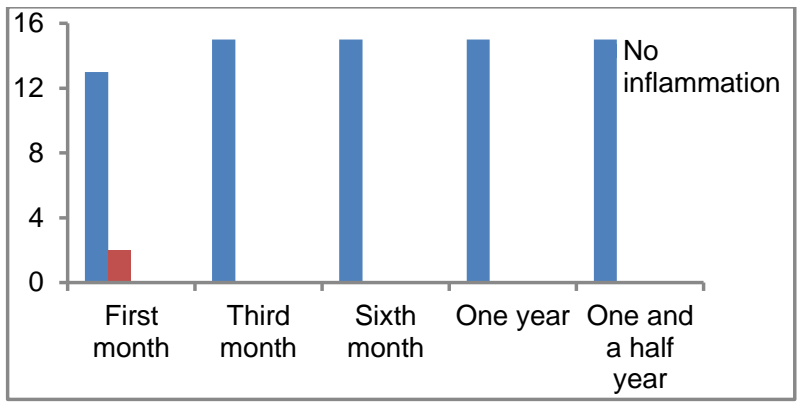

Fig. 2: Bar Chart of Gingival Index.

Study of pain during first month, third month, sixth month, one year and one and a half years

The presence of pain during the first, third, sixth month, one year and one and a half years for the patients is studied. The frequency distribution is given below.

Table 4: Frequency Distribution of Pain

\begin{tabular}{|c|c|c|c|c|c|c|}
\hline Pain & $\begin{array}{l}\text { Month } \\
\text { First month }\end{array}$ & Third month & Sixth month & One year & One and a half year & Total \\
\hline No pain & 15 & 15 & 15 & 15 & 15 & 45 \\
\hline Mild & 0 & 0 & 0 & 0 & 0 & 0 \\
\hline Severe & 0 & 0 & 0 & 0 & 0 & 0 \\
\hline Total & 15 & 15 & 15 & 15 & 15 & 45 \\
\hline
\end{tabular}

From the above table it can be observed that none of the patients had any severity - mild, moderate and severe of pain. The bar chart is also given below.

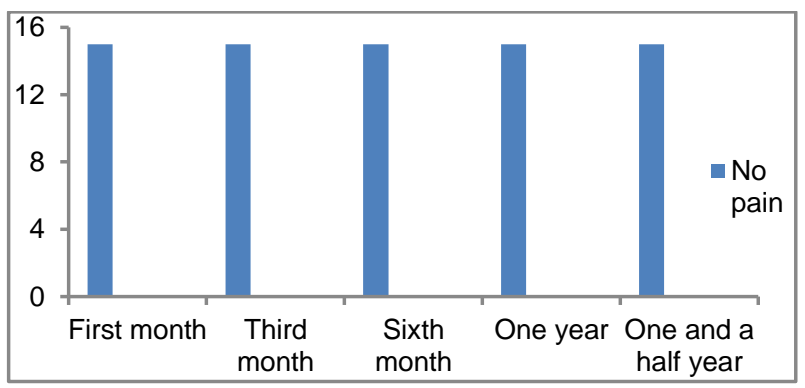

Fig. 3: Bar Chart of Pain.

Study of peri implantitis during first month, third month, sixth month, one year and one and a half years 
The presence of peri implantitis during the first, third, sixth month, one year and one and a half years for the patients is studied. The frequency distribution is given below.

Table 5: Frequency Distribution of Peri Implantitis

\begin{tabular}{lllllll}
\hline Peri implantitis & Month & & & & & Total \\
& First month & Third month & Sixth month & One year & One and a half year & \\
\hline No & 15 & 15 & 15 & 15 & 15 & 45 \\
Yes & 0 & 0 & 0 & 0 & 0 & 0 \\
Total & 15 & 15 & 15 & 15 & 15 & 45 \\
\hline
\end{tabular}

From the above table it can be observed that none of the patients had any symptoms of peri implantitis.

The bar chart is also given below.

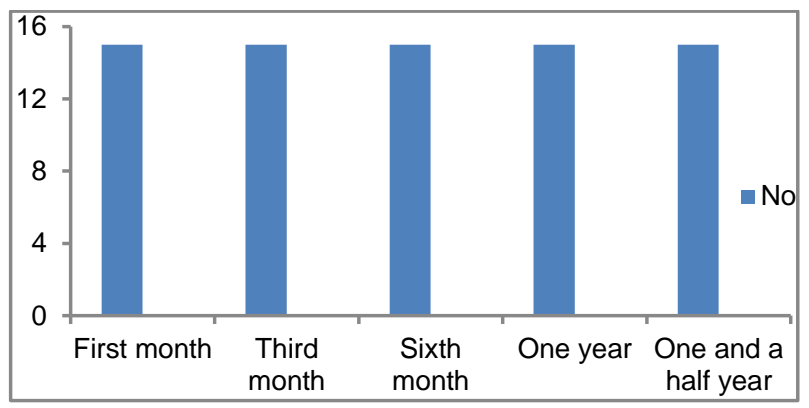

Fig. 4: Bar Chart of Peri Implantitis.

Study of mobility periotest during first month, third month, sixth month, one year and one and a half years

The presence of mobility periotest during the first, third, sixth month, one year and one and a half years for the patients is studied. The frequency distribution is given below.

Table 6: Frequency Distribution of Mobility Periotest

\begin{tabular}{|c|c|c|c|c|c|c|}
\hline \multirow[b]{2}{*}{ Mobility periotest } & \multicolumn{4}{|l|}{ Month } & \multirow[b]{2}{*}{$\begin{array}{l}\text { One and a half } \\
\text { year }\end{array}$} & \multirow[b]{2}{*}{ Total } \\
\hline & First month & Third month & Sixth month & One year & & \\
\hline Grade 0 & 15 & 15 & 15 & 15 & 15 & 45 \\
\hline Grade 1 & 0 & 0 & 0 & 0 & 0 & 0 \\
\hline Grade 2 & 0 & 0 & 0 & 0 & 0 & 0 \\
\hline Grade 3 & 0 & 0 & 0 & 0 & 0 & 0 \\
\hline Total & 15 & 15 & 15 & 15 & 15 & 45 \\
\hline
\end{tabular}

From the above table it can be observed that all the 45 patients, 15 patients each month had grade 0 mobility periotest.

The bar chart is also given below.

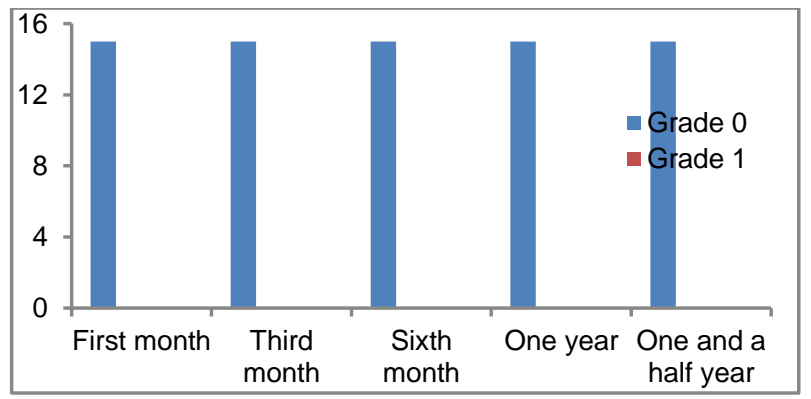

Fig. 5: Bar Chart of Mobility Periotest.

Comparison of mobility periotest among the different time points

Repeated measures ANOVA is used to test the null hypothesis that there is no significant difference in mean mobility periotest among the different time points - first month, third month, sixth month, one year and one and a half years. The results are given below.

Table 7: Descriptive Statistics

\begin{tabular}{lll}
\hline & Mean & Std. Deviation \\
\hline Mobility 1 month & -.107 & 1.515 \\
Mobility 3 month & -2.153 & 1.125 \\
Mobility 6 month & -2.840 & .842 \\
Mobility 1 year & -3.153 & .655 \\
Mobility 1 and half year & -3.447 & .614 \\
\hline
\end{tabular}

The descriptive statistics suggest that the mean mobility periotest decreases as the time period increases.

Table 8: Multivariate Tests

\begin{tabular}{lllll}
\hline Effect & Wilks' Lambda Value & F & Hypothesis df & Error df \\
\hline Time & .063 & 40.713 & 4.000 & Sig. \\
\hline
\end{tabular}


From the above table it can be concluded that there is significant difference in mean mobility periotest among the different time points first month, third month, sixth month, one year and one and a half years. The post-hoc test is conducted and the results are given below.

\begin{tabular}{|c|c|c|c|c|}
\hline (I) Time & (J) Time & Mean Difference (I-J) & Std. Error & Sig. \\
\hline \multirow{4}{*}{1 Month } & 3 Month & 2.047 & 0.324 & 0.000 \\
\hline & 6 Month & 2.733 & 0.304 & 0.000 \\
\hline & 1 year & 3.047 & 0.325 & 0.000 \\
\hline & 1 and a half year & 3.340 & 0.285 & 0.000 \\
\hline \multirow{4}{*}{3 Month } & 1 Month & -2.047 & 0.324 & 0.000 \\
\hline & 6 Month & 0.687 & 0.219 & 0.007 \\
\hline & 1 year & 1.000 & 0.238 & 0.001 \\
\hline & 1 and a half year & 1.293 & 0.230 & 0.000 \\
\hline \multirow{4}{*}{6 Month } & 1 Month & -2.733 & 0.304 & 0.000 \\
\hline & 3 Month & -0.687 & 0.219 & 0.007 \\
\hline & 1 year & 0.313 & 0.104 & 0.009 \\
\hline & 1 and a half year & 0.607 & 0.152 & 0.001 \\
\hline \multirow{4}{*}{1 year } & 1 Month & -3.047 & 0.325 & 0.000 \\
\hline & 3 Month & -1.000 & 0.238 & 0.001 \\
\hline & 6 Month & -0.313 & 0.104 & 0.009 \\
\hline & 1 and a half year & 0.293 & 0.100 & 0.011 \\
\hline \multirow{4}{*}{1 and a half year } & 1 Month & -3.340 & 0.285 & 0.000 \\
\hline & 3 Month & -1.293 & 0.230 & 0.000 \\
\hline & 6 Month & -0.607 & 0.152 & 0.001 \\
\hline & 1 year & -0.293 & 0.100 & 0.011 \\
\hline
\end{tabular}

From the above table it can be observed that there is significant difference in mean mobility periotest among each pair of time periods. The profile plot is given below.

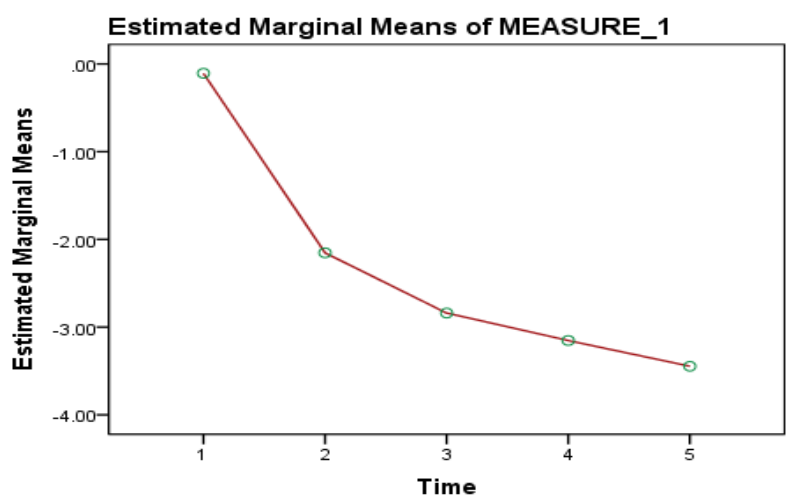

Fig. 6: Profile Plot of Mobility Periotest.

In the above plot the data point rounded is the mean mobility periotest for each time period. From the above test it can be concluded that the mean mobility periotest decreases from 1 month to one and a half years.

\section{Discussion}

Hybrid implant is a combination of subperiosteal and endosteal implants.

Although there are evidences of implant placements even in the prehistoric times, according to literature reviews about surgically placed implants, the first implant system was of subperiosteal type proposed by Dahl ${ }^{2(\mathrm{p} 430)}$ and later on placed by Dr. Aaron ${ }^{3,4}$.It consisted of a metal frame work placed underneath the soft tissue above the alveolus with an abutment emerging from the surface to carry denture. This system has laid foundation to implant dentistry in early 1950s.Afterwards so many people modified the implant design and techniques of placement of superior steal implants and evaluated the drawbacks and various rectifications were given for the same,,the latest being the use of hydroxyapatite coating of the implants ${ }^{5}$ and ct guided techniques ${ }^{6}$ of subpeioteal implant placement ${ }^{7}$. Many authors had reported the success of subperiosteal implants more than $80 \%$, $9,10,11,12,13,14$. The common drawbacks of the subperiosteal implant as reported by literature are crude impression techniques,failure of adaptation of the plate to the alveolar bone surface ,long operative time ,multilple interventions, need for general anesthesia setup and post operatively infection ,mobility, plate exposure etc.

The introduction of endosseous implant by Branemark ${ }^{15,16}$ and the concept of ossepintegration in titanium endosseous implant almost faded away the use of superosteal implant .The concept of osseointegraation and the biocompatibility of titanium are well proven according to literature review ${ }^{16,17,18,19}$. The problem which arises incase of maxillary posterior edentulous areas for endosseous implants is the need for adequate vertical and bucco-palatal width of the alveolar bone to which the implant is placed.In posterior edentulous maxilla there often will be reduced bone height and width due to the pneumatization of maxillary sinus which necessitate the need for bone augmentation either intrasinus or extra sinus. According to Cawood et $\mathrm{al}^{20}$ in patients with bone volume less than $10 \mathrm{~mm}$ in the vertical aspect and $4 \mathrm{~mm}$ in the horizontal aspect class V to class VI the prognosis for conventional treatment with osseointegrated implants has been considered poor.Various methods for sinus augmentation,techniques to avoid the maxillary sinus and to increase the bone height of posterior maxilla are available in literature ${ }^{21-33}$.All these techniques are technique sensitive ,need expensive equipment ,more operating time and expensive for the patient.Also the need for sinus augmentation and the quality of newly formed bone after augmentation are debatable ${ }^{34-40}$. The blade implants ${ }^{41-43}$ which are told to compensate for the reduced width of the edentulous sites-knife edges are also debatable. 
Hybrid implant is designed to overcome certain limitations of the current implant system. The plate of the implant can be well adapted to the alveolar bone avoiding the lack of proper adaptation in subperiosteal implant .The implant is anchored to the alveolar bone with titanium screws with very well form the endosseous component of the implant system. Eventhough the screw tips go into the maxillary sinus ,literature reviews ${ }^{34,44}$ and our own clinical experience with hybrid implant system has proven to be with least complications and are well tolerated by the patients.Intraoperatively only minimum structures will be encounterd as the plane of surgery is subperiosteal.Hydroxyapetite coating of the implant permit new bone formation over the implant adding more strength to the implant along with osseointegration of the titanium. In our evaluation there was a healthy gingival cuff around the abutment of all evaluated hybrid implant .The post operative swelling was also not more than with a minor oral surgery.The pain was well tolerated by all the patients with routine analgesics postperatively one week. The implant was free of any complication during our evaluation period of six months. The evaluation of mobility with PERIOTEST ${ }^{45-47}$ also found to sufficient to prove the stability of the implant system. The stability of the implant seemed to be increasing over the months.

\section{Conclusion}

Hybrid implant system is an effective system for the rehabilitation of posterior maxillary edentulous spaces with inadequate bone for endosseous implant placement and also cost effective and patient friendly. According to our study it proves to be a safer alternative for sinus lift and bone grafting.Further long term studies and multicenter studies and modifications in design are needed for a more confirmatory efficacy about the hybrid implant system

\section{Acknowledgments and disclosure statements}

The authors have no conflicts of interest to disclose. No external funding, apart from the support of the authors' institution, was available for this study.

\section{References}

[1] Varghese Mani, K. K. Sivaprasad, Arun George, V. Sankar Vinod, Miriam Mathew \& Susan Paul.Hybrid Implant: A Novel Implant System.J. Maxillofac. Oral Surg 14:720-777, 2015. https://doi.org/10.1007/s12663-014-0722-9.

[2] Misch CE contemporary implant dentistry .2nded.St.Louis, Mo: Mosby; 1999. https://doi.org/10.1097/00008505-199901000-00013.

[3] Sullivan RM. Implant dentistry and the concept of osseointegration: a historical perspective. J Calif Dent Assoc 2001; 29:737-45.

[4] History [Internet]. Chicago (IL): American Academy of Implant Dentistry [cited 2014 Apr 22]. Available from: http://www.aaid. com/about/History.html.

[5] Mish CE, Dietsh F. The unilateral mandibular superiosteal implant - indications and technique .J Oral Implantol .1991; 8:21-27.

[6] Harold P. Truit, Robert James, Alan Altman and Phillip Boyne. Use of computer tomography in subperiosteal implant therapy .J Prosthet Dentistry 59:474-477, 1988. https://doi.org/10.1016/0022-3913(88)90045-5.

[7] Mish CE, Dietsh F. The unilateral mandibular superiosteal implant - indications and technique .J Oral Implantol .1991; 8:21-27.

[8] Randall W. Kreutz and Seymour J. Carr. Bilateral oronasal fistulas secondary to an infected maxillary subperiosteal implant.oral surg. Oral med. oral pathol., 61:230-232,1986. https://doi.org/10.1016/0030-4220(86)90366-X.

[9] Bailey J.H.,Yanase, R.T.\& Bodine ,R.L (1988) The mandibular subperiosteal implant denture : A fourteen -year study .Journal of prosthetic Dentistry. https://doi.org/10.1016/0022-3913(88)90285-5.

[10] James, R.A., Lozada J.L., Truit, PH.,Foust, B. E.\& Jovanovic, SA. (1988) Subperiosteal Implants. Journal of the California Dental Association16:10-14.

[11] Golec, T.S. (1989) The mandibular full subperiosteal implant-Aten -year review of 202 cases. Journal of Oral Implantology 15;179-185.

[12] Benjamin L. Long - term retrospective studies on the CT Scan CAT/CAD one stage surgery hydroxyapatite coated subperiosteal implants, including human functional retrievals. Dent Clin North Am .1992; 36:77-93.

[13] Yanase, R. T., Bodine,R.L.,Tom, J.F.M.D. \& White ,S.N.(1994) Themandibular subperiosteal implant denture :A prospective survival study. Journal of Prosthetic dentistry 71:369-374. https://doi.org/10.1016/0022-3913(94)90096-5.

[14] O"Roark Survival rate of dental implants :an individual practitioners anecdotal review of 25 years of experience.J Oral implantol.1994;20:43-47.

[15] Find out who was responsible for starting dental implant history [Internet]. [place unknown]: Dental-Health-Advice [cited 2014 Apr 22]. Available from: http://www.dental-health-advice.com/dental- implant-history.html.

[16] Branemark, P.-I., Hansson, B.O. Adell ,R., Breine,U., Lindstrom, J., Hallen, O.\& Ohman,A.: Osseointegrated implants in thetreatment of the edentulous jaw Experience from a 10-year period. Scand, J. Plast .Reconstr.SURG. 1977: 11: Suppl 16; and as a monograph from Almqvist \& Wiksell International, Stockholm 1977.

[17] Albrektsson, T., Branemark, P-I ., Hansson, H-A., and Lindstrom ,J.: Osseointegrated titanium implants ensuring a long lasting bone - to- implant anchorage in man .Acta Orthop Scand 52:155,1981. https://doi.org/10.3109/17453678108991776.

[18] Adell, R., Lekholm, U., Rockier, B., and Branemark, P-I.: A15-year study of osseointegrated implants in the treatment ofthe edentulous jaw. Int J Oral Surg 1\&387, 1981. https://doi.org/10.1016/S0300-9785(81)80077-4.

[19] H.A. Hansson, T. Albrektsson, and P-I. Branemark.Structural aspects of the interface between tissue and titanium implants .J Prosthet Dentistry 50:108- 113.1983. https://doi.org/10.1016/0022-3913(83)90175-0.

[20] Cawood JI,Howell RA .A classification of the edentulous jaw .Int J Oral Maxillofac Surg 1988:17:232-6. https://doi.org/10.1016/S09015027(88)80047-X.

[21] Albrektsson T, Branemark P-I,Eriksson A,et al:The preformed autologous bone graft.Scand J Plast Reconstr Surg 12:215,1978. https://doi.org/10.3109/02844317809012997.

[22] Boyne PJ. James RA. Grafting of the maxillary sinus floor with autogenous marrow and bone.J Oral Surg 1980; 38(8):613-6.

[23] Breine U, Branemark PI: Reconstruction of alveolar jaw bone.Scand J Plast Reconstr Surg 14:23, 1980. https://doi.org/10.3109/02844318009105733.

[24] Sailer Hf.A new method of inserting endosseous implants in totally atrophic maxillae.J Cranio-Max-Fac Surg 1989:30:299-305. https://doi.org/10.1016/S1010-5182(89)80057-5.

[25] J. I. Cawood, P.J.W.Stoelinga,J.J.A.Brouns:Reconstruction of the severely resorbed (Class VI) maxilla.A two-step procedure. Int .J. Oral Maxillofacial. Surg 1994; 23:219-225. https://doi.org/10.1016/S0901-5027(05)80374-1.

[26] Summers RB: A new concept in maxillary implant surgery: The osteotome technique. Compend Contin Educ Dent 15:152, 1994.

[27] Davarpanah M, Martinez H, Tecucianu J, et al: The modified osteotome technique. Int J Period Rest Dent 21:599, 2001.

[28] Torella F,Pitarch J,Cabanes G,et al:Ultrasonic ostectomy for the surgical approach of the maxillary sinus : A technical note .Int J Oral Maxillofac Implants 13:697,1998. 
[29] Darle C: Branemark system zygoma fixture, A unique solution for rehabilitation of the severely resorbed maxilla;The zygoma option (ed2). Gothenburg, Sweden, Nobel Biocare AB, 2000.

[30] Krekmanow L.Placement of posterior mandibular and maxillary implants in patients with severe bone deficiency: a clinical report of procedure .Int J Oral Maxillofac Implants 15:405, 2000

[31] Parel SM,Branemark PI,Ohrnell LO,et al :Remote implant anchorage for the rehabilitation of maxillary defects.J Prosthet Dent 86:377,2001. https://doi.org/10.1067/mpr.2001.118874.

[32] Sotirakis EG, Gonshor A: Elevation of the maxillary sinus floor with hydraulic pressure. J Oral Implantol 31:197, 2005. https://doi.org/10.1563/1548-1336(2005)31[197:EOTMSF]2.0.CO;2.

[33] Summers RB: A new concept in maxillary implant surgery: The osteotome technique. Compend Contin Educ Dent 15:152, 1994.

[34] Joseph Choukroun, Antoine Diss, Alain Simonpieri,Marie -Odile Girard,Christian Schoeffler,Steve L.Dohan, Anthony J.J.Dohan,Jaafar Mouhyi,and David M.Dohan : Platelet -rich Fibrin (PRF) : A second - generation platelet concentrate.Part V: Histologic evaluations of PRF effects on bone allografts maturation in sinus lift..Oral Surg Oral Med Oral Pathol Oral Radiol Endod 2006: 101:299-303. https://doi.org/10.1016/j.tripleo.2005.07.012.

[35] P. I Branemark, R.Adell ,T.Albrektsson ,U.Lekholm, J.Lindstrom,B.Rockler. An experimental and clinical study of osseointegrated implants penetrating the nasal cavity and maxillary sinus.J Oral Maxillofac Surg42:497-505. https://doi.org/10.1016/0278-2391(84)90008-9.

[36] Tolman DE: Reconstructive procedures with endosseous implants in grafted bone : A review of the literature .Int J Oral Maxillofac Surg 17 $: 33,1988$.

[37] Joseph Choukroun, Antoine Diss, Alain Simonpieri,Marie -Odile Girard,Christian Schoeffler,Steve L.Dohan, Anthony J.J.Dohan,Jaafar Mouhyi,and David M.Dohan : Platelet -rich Fibrin (PRF) : A second - generation platelet concentrate.Part V: Histologic evaluations of PRF effects on bone allografts maturation in sinus lift..Oral Surg Oral Med Oral Pathol Oral Radiol Endod 2006: 101:299-303. https://doi.org/10.1016/j.tripleo.2005.07.012.

[38] Nyström E, Nilson H, Gunne J, Lundgren S. A 9-14 year follow-up of onlay bone grafting in the atrophic maxilla. Int J Oral Maxillofac Surg2009; 38:111-6. https://doi.org/10.1016/j.ijom.2008.10.008.

[39] Jee-Won Moon,Dong-Seok-Sohn, Jeong-Uk-Heo,Hong-In Shin, and Jae-Kyun Jung.New Bone Formation in the maxillarysinus Using Peripheral Venous BloodAlone.J Oral Maxillofac Surg 69:2357-2367, 2011 https://doi.org/10.1016/j.joms.2011.02.092.

[40] Nuray Yilmaz Altintas,Figen Cizmeci Senel, Saadettin Kayımaz, Fatih Taskesen,and A. Alper Pampu.Comparative Radiologic Analyses Of NewlyFormed Bone After Maxillary SinusAugmentation With And WithoutBone Grafting.J Oral Maxillofac Surg 71:1520-1530, 2013. https://doi.org/10.1016/j.joms.2013.04.036.

[41] A. P. F. assi, . Pioto, . P. Faverani, . Canestraro, F. . K. Fonta o Maxillary sinus lift without grafting, and simultaneous implant placement: a prospective clinical study with a 51-month follow-up. Int. J. Oral Maxillofac. Surg. 2015; 44: 902-907. https://doi.org/10.1016/j.ijom.2015.03.016.

[42] Leonard I.Linkow. Endosseous blade-vent implants: A two -year report. J Prosthet Dentistry: 441-448. https://doi.org/10.1016/00223913(70)90011-9.

[43] Joseph R. Natiella, Jack E. Armitage, Michael A . Meenaghan , Charles S. Lipani and George W. Greene, Buffalo, N.Y. Oral Surg.36:336342.,1973. https://doi.org/10.1016/0030-4220(73)90211-9.

[44] C. W. Svare, W. E. LaVelle, P. E. Delong, J.Kent and D. Weber. Coated versus non-proplast -coated endosseous blade-vent dental implants. Oral Surg 40:2- 7.1975. https://doi.org/10.1016/0030-4220(75)90336-9.

[45] Mitsuru Motoyoshi, Rina Sanuki-Suzuki, Yasuki Uchida, Akari Saiki, and Noriyoshi Shimizu.Maxillary sinus perforation by orthodontic anchor screws.Journal of Oral Science, Vol. 57, No. 2, 95-100, 2015. https://doi.org/10.2334/josnusd.57.95.

[46] Olive, J., Aparicio, C., 1990. Periotest method as a measure of osseointegrated oral implant stability. Int. J. Oral Maxillofac. Implants 5, 390-400.

[47] Teerlinck, J., Quirynen, M., Darius, P., van Steenberghe, D., 1991. Periotest: an objective clinical diagnosis of bone apposition toward implants. Int. J. Oral Maxillofac. Implants 6, 55-61.

[48] Drago, C.J., 2000. A prospective study to assess osseointegration of dental endosseous implants with the Periotest instrument. Int. J. Oral Maxillofac. Implants 15, 389-395. 